\title{
Gait analysis of walking before and after medial opening wedge high tibial osteotomy.
}

\section{Martin Lind MD, PhD}

Sports trauma division, Dept. of Orthopedics, Aarhus University Hospital

Musculoskeletal Research Centre, La Trobe University, Melbourne, Australia

Jodie McClelland PhD

Musculoskeletal Research Centre, La Trobe University, Melbourne, Australia

Joanne E Wittwer B App Sc (Pty)

Musculoskeletal Research Centre, La Trobe University, Melbourne, Australia

\section{Timothy S Whitehead FRACS}

Musculoskeletal Research Centre, La Trobe University, Melbourne, Australia

Julian A Feller FRACS

Musculoskeletal Research Centre, La Trobe University, Melbourne, Australia

Kate E Webster PhD

Musculoskeletal Research Centre, La Trobe University, Melbourne, Australia

\section{Corresponding Authors:}

Martin Lind, MD.

Division of Sportstrauma, Orthopaedic Department;

Aarhus University Hospital, Tage Hansensgade 2, 8000 Aarhus C, Denmark, E-mail: Martinlind@dadlnet.dk

Tel: +45 89497094 Fax: +45 89497462 
Kate Webster PhD

Musculoskeletal Research Centre

La Trobe University

Bundoora VIC 3086 Australia

E-mail: k.webster@latrobe.edu.au

Tel: +61 394795796 Fax: +61 394795415 


\section{Abstract}

\section{Introduction}

Medial opening wedge high tibial osteotomy (HTO) is used to treat medial compartment osteoarthritis $(\mathrm{OA})$ of the knee. HTO shifts the weight bearing line from the medial compartment into the lateral compartment. The aim of this study was to investigate the functional biomechanical consequences of this alteration in alignment.

\section{Methods}

Eleven male patients with medial compartment osteoarthritis underwent 3-dimensional gait analysis during level walking before and 12 months after medial opening wedge HTO. Nine male control subjects of a similar age were also tested using the same protocol. Sagittal and coronal angles and moments in both operated and non-operated knees were compared. Pre and postoperative radiographic coronal plane alignment was also measured.

\section{Results}

Walking speed increased significantly postoperatively $(p=0.0001)$ and was not different from controls. Preoperatively maximum knee flexion in stance was reduced compared to control $(p=0.02)$. Postoperatively maximum knee flexion increased significantly $(p=0.005)$ and was the same as the controls. Similar changes were observed for the maximum knee flexion moment. The mean maximum varus angle during stance was reduced from $13.5^{\circ}$ preoperatively to $5.4^{\circ}$ postoperatively $(p=0.0001)$ compared to $\left(6.8^{\circ}\right)$ in controls. The mean maximum adduction moment also reduced from 3.9 to $2.7(\% \mathrm{Bw} / \mathrm{ht}, \mathrm{p}=0.02)$, compared to 3.6 in control subjects. Interestingly, the adduction moments in the nonoperated knee increased postoperatively from 3.3 to 4.1 (\% Bw/ht, $\mathrm{p}=0.02)$. The mean radiological mechanical alignment was changed from 172 degrees preoperatively to 180 degrees postoperatively $(p<0.001)$.

\section{Conclusion}

HTO resulted in normalisation of several dynamic knee function parameters such as walking speed, knee flexion, and external knee flexion moment. As anticipated HTO reduced the varus angle and adduction moments of the operated knee. An increased adduction moment in the non-operated knee over the first postoperative year was found.

Level of evidence: Level 3, Prospective case-control clinical laboratory study.

Keywords: 
High tibial osteotomy. Opening wedge, osteoarthritis, gait analysis, knee moments 


\section{INTRODUCTION}

High tibial osteotomy (HTO) is an established surgical treatment for symptomatic medial compartment osteoarthritis of the knee. This procedure is commonly performed in young, active patients not suited to joint replacement and several studies have demonstrated good short to midterm clinical outcomes for this group [8, 10,11]. The aim of the procedure is to alter the mechanical axis so that the weight bearing line (WBL) is shifted into the lateral compartment of the knee, thereby reducing load through the affected medial compartment $[7,10,21]$. The procedure can be performed using either a lateral closing wedge or a medial opening wedge technique.

Studies have demonstrated that during the gait cycle, people with knee osteoarthritis and varus alignment walk with specific knee biomechanics and muscular function [3]. In particular, an increased knee adduction moment is typically observed in patients with medial knee osteoarthritis and has also been associated with accelerated disease progression [17]. Additionally, patients with medial knee osteoarthritis tend to walk with increased muscle co-contraction, increased frontal plane laxity and quadriceps weakness $[2,6,26]$.

Recent studies have used three dimensional motion analysis to demonstrate that in addition to restoring more normal static alignment of the lower limb, HTO is also successful in reducing the excessive knee adduction moment that characterises osteoarthritic gait $[4,6,22,23,27]$. However, it is not clear how the post-operative adduction moment relates to normal gait as there have been no reported comparisons to unimpaired controls. Similarly, although there is some evidence that sagittal plane knee moments and kinematics are altered following HTO [4], it is not known if these changes enable more normal gait. Relief of OA symptoms af HTO could improve sagittal gait parameters by enabling higher walking speed, higher flexion angles and higher flexion moments.

The incidence of bilateral knee osteoarthritis has been reported to be as high as $37.2 \%$ [17]. The influence of the HTO-altered alignment of one limb on the biomechanics of the contralateral knee has also not yet been investigated.

The aim of this study was, therefore, to use three dimensional motion analyses to investigate the knee kinematics and kinetics of patients who had undergone a medial 
opening wedge $\mathrm{HTO}$ and compare these findings with data from a control population. In addition, we investigated the effect of HTO on the biomechanics of the contralateral limb. The primary hypothesis of this study was that a medial opening wedge HTO would result in a reduction of the adduction moment to less than normal. It was also hypothesised that HTO also would result in normalized sagittal plane kinematics and kinetics. 


\section{METHODS}

\section{Participants}

Patients who were scheduled for a medial opening wedge high tibial osteotomy for medial compartment osteoarthritis between December 2006 and January 2008 were assessed for eligibility to participate in this study. Patients were excluded if they had other documented orthopaedic, neurological or visual disturbances that may affect gait, including joint replacements of the hips, knees and ankles. Thirteen male patients satisfied the inclusion criteria and agreed to participate in the study that involved three dimensional motion analysis prior to surgery and at one year post-operatively (62 weeks (16)). Due to technical difficulties during data sampling, data were collected from only 11 of these participants.

All participants received a medial opening wedge HTO stabilized with a medial plate and screws. The VS osteotomi plate from Biomet was used in 7 patients and The Puddu plate from Arthrex was used in 4 patients. Pre operatively, the degree of opening of the medial wedge was calculated so that the weight bearing line from the centre of the femoral head to the centre of the talus passed through the knee joint at a point $62.5 \%$ of the width of the tibial plateau from its medial border [9].

The control group consisted of 9 male participants who had not undergone any knee joint surgery or reported weight-bearing pain in any lower limb joint. The control participants were selected based on similarity of age and sex to the members of the HTO group. The patients and controls were similar in terms of age and body mass index. The age of HTO patients were 46 (range 34-57) years and the age of controls 47 years (range 32-61). The BMI HTO patients were 28 (range 25-31) and the age of controls 25(range 21-32). 
Ethics approval for the study was obtained from the institutional ethics committee and informed consent was obtained from all participants.

\section{Radiographic analysis.}

Long leg weight bearing anteroposterior (AP) radiographs in double limb stance were obtained for all HTO participants both preoperatively and at 12 months following surgery. Limb alignment in the coronal plane was measured using three separate methods for both the operated and contralateral limbs. The mechanical axis was defined as the angle made between a line drawn from the centre of the femoral head to the centre of the knee (the midpoint between the tibial spines), and a line drawn from the centre of the talus to the centre of the knee. The weight bearing line was defined as the line created from the centre of the femoral head to the centre of the talus [9]. At the knee, the distance of this line from the medial border of the tibial plateau was calculated as a percentage of the width of the tibia at the knee joint. The radiographic data from one patient was lost due to lost radiographs.

\section{Equipment}

A 10 camera Vicon MX3 Motion Analysis System (Vicon, Oxford, UK) was used to collect kinematic data at a sampling rate of $100 \mathrm{~Hz}$. Two force plates embedded into a 10 metre walkway (Kistler, Switzerland and AMTI, Watertown, MA, USA) were used to collect kinetic data at a sampling rate of $400 \mathrm{~Hz}$.

\section{Gait analysis protocol}

All participants attended the gait laboratory for motion analysis testing at two weeks prior to surgery, and at 12 months (mean 62,7 weeks, range 48-96 weeks) following surgery.

Thirteen $14 \mathrm{~mm}$ diameter reflective markers were placed over anatomical landmarks according to the Helen Hayes Marker System $[9,14]$. To summarise, markers were placed centrally over the sacrum, and bilaterally over the anterior superior iliac spines, lateral femoral epicondyles, medial and lateral malleoli, calcanei and the base of the $2^{\text {nd }}$ metatarsals. Markers on $5 \mathrm{~cm}$ wands were also placed bilaterally on the lateral aspect of the thigh and leg. A knee alignment device was applied during a static subject calibration 
to calculate the lower limb joint centres using Plug-in-gait (Vicon, Oxford Metrics, Oxford UK).

Participants were instructed to walk the length of a 10 meter walkway repeatedly until they felt comfortable with the procedure and had acquired a consistent self-selected walking speed. Although data were recorded over the length of the walkway, only the strides incorporating contact of a single foot within either one or both forceplates were included in the analysis. Participants were instructed to walk repeatedly along the walkway at their self-selected comfortable speed until 6 successful strides for each limb were collected. They were not informed of the presence of the forceplates so they would not alter their gait pattern to ensure striking them.

\section{Data analysis}

PlugIn Gait (Vicon, Oxford Metrics, Oxford, UK) was used to calculate joint kinematics during walking. Joint moments were calculated using standard inverse dynamics. Joint moments were also normalised to each participant's bodyweight and height (represented as \%Bw-Ht [16] and are reported as external joint moments throughout this manuscript. Data from each stride were time normalised to $100 \%$ of the gait cycle where initial contact of a limb inside a forceplate was defined as $0 \%$ and the following ground contact of the same limb was defined as $100 \%$.

\section{Statistical analysis}

The data from 6 strides of the same limb were combined to form an average that represented a typical stride for a single limb of each participant. From each participant's average data, the peak kinematic and kinetic parameters in the sagittal and coronal planes of movement were identified and included for analysis. Joint moments were also normalised to each participant's bodyweight and height (represented as \%Bw-Ht). For the control group data and the operated limb of the HTO participants, the following variables were recorded : maximum knee flexion, extension and adduction angles during stance phase, maximum knee flexion angle during swing phase, the maximum knee flexor and 
extensor moments, the adduction moment during early stance and the adduction moment during late stance.

For each gait variable, the individual participant averages of were tested for normality using the Kolmogorov-Smirnov test. For comparisons between controls, preoperative and postoperative data one-way ANOVA was performed initially to determine whether differences between groups existed. In cases where the $\mathrm{F}$ ratio was significant, post-hoc comparisons were performed to determine specific differences between groups. Bonferroni corrections for multiple comparisons were made between groups. 


\section{RESULTS}

There were no surgical complications in the 11 patients.

\section{Radiographic Data}

The pre and post-operative radiographic measurements are summarised in Table 1. Preoperatively, the average mechanical axis of the HTO participants was 8 degrees of varus $\left(\mathrm{SD}=2.8^{\circ}\right)$. Following $\mathrm{HTO}$, the average mechanical axis was 0 degrees of valgus $\left(\mathrm{SD}=2.1^{\circ}\right)$. The weightbearing line changed from a pre-operative mean position of $13 \%$ (SD $=15 \%)$ to $56 \%(S D=13 \%)$ post-operatively.

\section{Walking speed and stride length}

The self-selected walking speed of the HTO participants increased significantly from 1.22 $\mathrm{m} / \mathrm{sec}(\mathrm{SD}=0.13 \mathrm{~m} / \mathrm{sec})$ preoperatively to $1.43 \mathrm{~m} / \mathrm{sec}(0.18 \mathrm{~m} / \mathrm{sec})$ postoperatively $(p<0.0001)$. The postoperative walking speed was not significantly different from the control group $(1.54 \mathrm{~m} / \mathrm{sec}, \mathrm{SD}=0.18 \mathrm{~m} / \mathrm{sec})$. Similarly the stride length increased from $1.37 \mathrm{~m}$ preoperatively to $1.48 \mathrm{~m}$ postoperatively in the HTO group, and again the postoperative HTO stride length was not different from controls $(1.48 \mathrm{~m}, \mathrm{SD}=0.14 \mathrm{~m})$.

\section{Kinematics of the Operated Knee}

The profile of the group averages for the sagittal plane knee angles are shown in Figure 1. The comparisons of the peak sagittal plane knee kinematics are summarised in Table 2. Prior to surgery, the HTO participants walked with significantly less peak knee flexion during stance $\left(11.0^{\circ}, \mathrm{SD}=8.7^{\circ}\right)$ compared to controls $\left(19.5^{\circ}, \mathrm{SD}=3.6^{\circ} ; \mathrm{p}<0.02\right)$. However, following surgery, the peak knee flexion during stance increased significantly to $19.5^{\circ}$ $\left(S D=5.4^{\circ} ; p<0.02\right)$ which was not different from the control group. Knee flexion for the nonoperated extremity was not different from postoperative values of the operated knee or the control group values. In contrast, the amount of knee extension during stance for the HTO participants was not different from controls $\left(-0.2^{\circ}, \mathrm{SD}=3.7^{\circ}\right)$ either before $\left(2.2^{\circ}, \mathrm{SD}=6.3^{\circ}\right)$ or after $\left(-2.6^{\circ}, \mathrm{SD}=5.9^{\circ}\right)$ surgery. With extension values around $1^{\circ}$ the contralateral knee demonstrated similar levels of extension both pre- and postoperatively. There was also no significant difference in the amount of knee flexion during swing phase between the preoperative $\left(55.5^{\circ}, \mathrm{SD}=4.8^{\circ}\right)$, post-operative $\left(58.7^{\circ}, \mathrm{SD}=4.8^{\circ}\right)$ and control groups $\left(57.3^{\circ}\right.$, $\left.\mathrm{SD}=4.8^{\circ}\right)$. For the non-operated extremity maximum swing phase were similar to postoperative and control levels. 
The coronal plane kinematic profile is shown in Figure 2, which clearly demonstrates a large difference in the varus alignment of patients between the pre-operative and postoperative assessment. Comparison of the peak coronal plane kinematic data are summarised in Table 2. As expected, the pre-operative maximum knee adduction angle for the HTO participants $\left(13.5^{\circ}, \mathrm{SD}=4.1^{\circ}\right)$ was significantly larger than that of the control group $\left(6.8^{\circ}, \mathrm{SD}=2.8^{\circ} ; \mathrm{p}<0.001\right)$. Following surgery, the maximum knee adduction angle was significantly reduced $\left(5.4^{\circ}, \mathrm{SD}=3.1^{\circ} ; \mathrm{p}<0.001\right)$ and again, was not different from the control group. Adduction angles in the non-operated knee was very similar to control values with $7.2^{\circ}$ preoperatively and $8.7^{\circ}$ postoperatively.

\section{Moments of the Operated Knee}

The sagittal plane knee moment profiles for each group are shown in Figure 3, and comparisons of peak data for both the sagittal and coronal planes are summarised in Table 3. Pre-operatively, the patients walked with significantly reduced peak knee flexor moments during early stance phase $(1.5, \mathrm{SD}=1.5 \% \mathrm{Bw}-\mathrm{Ht})$ compared to the control group (3.9, SD=1.2 \%Bw-Ht). The flexor moment was normalized at 12 months following surgery when the HTO participants walked with a peak knee flexor moment of $3.6 \% \mathrm{Bw}-\mathrm{Ht}(\mathrm{SD}=1.5)$ As with the knee extension angles, the extensor moments in late stance were not different between the groups.

The group average coronal plane knee moments throughout stance are shown in Figure 4. There was no difference in the knee adduction moment between the HTO participants prior to surgery $(3.9, \mathrm{SD}=0.7 \% \mathrm{Bw}-\mathrm{Ht})$ and the control group $(3.6, \mathrm{SD}=0.7$ $\% B w-H t)$. As expected, following surgery the HTO participants walked with a significantly reduced knee adduction moment $(2.8, \mathrm{SD}=0.9 \% \mathrm{Bw}-\mathrm{Ht})$ when compared to their pre-operative adduction moment $(3.9, p<0.02)$.

In the sagittal plane, the knee flexor moment of the contralateral limb increased significantly from the pre-operative assessment $(3.0, \mathrm{SD}=1.0 \% \mathrm{Bw}-\mathrm{Ht})$ to the postoperative assessment $(4.0, \mathrm{SD}=1.6 \% \mathrm{Bw}-\mathrm{Ht}) \mathrm{p}=0.03$. In the coronal plane, the preoperative adduction knee angle $\left(7.2^{\circ}, \mathrm{SD}=3.5^{\circ}\right)$ increased to $\left(8.7^{\circ}, \mathrm{SD}=4.5^{\circ}\right) \mathrm{p}=0.02$, and knee adduction moment $(3.3, \mathrm{SD}=0.8 \% \mathrm{Bw}-\mathrm{Ht})$ increased significantly following surgery (and $4.1, \mathrm{SD}=1.3 \% \mathrm{Bw}-\mathrm{Ht}$ ) $\mathrm{p}=0.02$. 


\section{Discussion}

This study demonstrated that by altering coronal limb alignment, a medial opening wedge HTO was able to improve and for some parameters normalize walking biomechanics. Although other studies have used gait analysis to demonstrate similar changes following HTO $[4,6,22,23,27]$, a comparison with a control group has only been described in one study previously [23]. In our study, walking speed and stride length as well as sagittal knee moments were normalised to control group values. As expected, the maximum knee adduction angle and coronal knee moments were reduced to levels less than those of the control group. These finding are similar to the findings of Ramsey et al. [23]. In their study however the surgical correction was more pronounced with an average postoperative weightbearing line of $73 \%$. This resulted in greater changes in both adduction angles and moments, but the necessity of such a high degree of correction can be questioned. The normalization of gait parameters after HTO may explain the symptomatic and quality of life improvements described in other studies [1, 8, 11, 13, 24].

We found improvements in sagittal biomechanical parameters from preoperative to the postoperative condition of the operated knee. The reduced OA symptoms that resulted from the HTO procedure is like to enable the patient to increase gait speed and thereby increasing maximal stance and swing flexion angles. Also the reduced pain level after HTO will enable improved quadriceps function that can increase flexor moments to the levels seen in the control group. A previous study has investigated maximal quadriceps strength after HTO and could not find improvement one year follow-up [16]. One possible reason for the discrepancy of this finding compared to our study, could be that they tested isometric strength whereas we have tested knee moments during normal gait.

Analysis of our patients prior to HTO demonstrated walking patterns with reduced knee flexion angles and sagittal knee moments in stance as well as increased knee adduction moments throughout the gait cycle. In the presence of varus alignment, the rate of progression of medial compartment osteoarthritis is increased due to an overloaded medial compartment and abnormal gait pattern [2, 6, 18, 25]. It is possible that the observed improvements in walking function and knee moments following HTO may slow the progression of medial compartment osteoarthritis, thereby delaying or in some cases preventing later conversion to arthroplasty. However, a possible disadvantage of this 
procedure may be the progression of lateral compartment degeneration due to the increased load through that compartment, especially in the case of over correction [11].

Although there was an alteration in coronal limb alignment following HTO, the correction (WBL 58\%) was slightly less than planned (WBL 62.5\%). A number of factors may have contributed to this minor difference. Under correction at the time of surgery and loss of correction postoperatively are the most likely factors. However, it is difficult to standardize patient position when taking radiographs thereby introducing the potential for measurement error. Despite this apparent slight under correction based on weightbearing axis, the improved walking function and reduction in adduction moments and angles to less than control values would suggest that the procedure was clinically successful and still fulfilled the aim of a coronal plane valgus overcorrection to off-load the medial knee compartment with OA.

Although some authors have previously correlated under correction with higher failure rates and poor patient satisfaction, most have studied lateral closing wedge techniques [8, 11,13 ]. While the optimal amount of correction following a medial opening wedge HTO is unknown it is likely to be less than for a lateral closing wedge procedure [4]. The medial opening wedge technique acts as a medial buttress and by preserving the lateral structures, recurrent varus deformity is less likely. Therefore weight bearing axis correction well in to the lateral compartment may not be necessary to effectively unload the medial compartment in the longer term.

Following HTO there was a slight, although statistically not significant, loss of extension in stance compared to both the preoperative state and to control subjects. Although not formally measured, one possible explanation may be an inadvertent increase in post operative tibial slope. Such an alteration in tibial slope after medial opening wedge HTO has been well described and is largely due to the anatomy of the tibia at the level of the osteotomy [15, 19, 20,28]. At this level, the tibia is triangular in cross section and the osteotomy wedge should be sloped in order to maintain the pre operative tibial slope [19]. Careful surgical technique is required to create an asymmetrical osteotomy with a posterior gap that is approximately twice as large as the anterior osteotomy gap.

The knee adduction moment in particular, is the gait parameter that has been most related to knee osteoarthritis. This moment, which acts to force the tibia into varus, has been validated as a reliable indicator of medial load $[5,29]$. The knee adduction moment is 
predominantly determined by the product of the ground reaction force and the frontal plane lever arm length (perpendicular distance from the knee joint centre to the ground reaction force). For the contralateral limb of the HTO participants, the maximum knee adduction angle and maximum flexor and adduction moments were analysed as these parameters have been associated with onset and progression of osteoarthritis [18].

An important finding of this study was that the biomechanics of the contralateral knee were significantly altered postoperatively, with an overall increase in the adduction angle and moments as well as the knee flexor moment. Although the exact mechanism of this is not clear, it is possible that the increased walking speed following surgery was partly responsible. It is also possible that factors such as altered body mass distribution and lateral trunk lean may contribute to these findings [12]. The long term consequences of these changes in gait patterns in the contralateral limb are not known and warrant further investigation, given their potential to increase the risk of knee osteoarthritis in that limb. Our finding of increased adduction moment over time in the contralateral knee is contrasted by the findings in the study by Birmingham et al [4]. In their study with a large material of more than $100 \mathrm{HTO}$ patients no change in knee adduction moment was found.

The presented study is strengthened by using a control group that is matched concerning sex, age and BMI. This enables evaluation of the degree of normalization of the investigated biomechanical parameters. A limitation of this study was the relatively small sample size, which make correlation of biomechanical data to clinical outcome data impossible. A number of statistically significant differences between preoperative and postoperative conditions were nonetheless reported. We determined that there was sufficient power $(80 \%)$ to detect large $(\mathrm{d}>0.8)$ effect sizes for improvements in gait parameters. However, it is possible that smaller effects were not detected.

\section{Conclusion}

HTO resulted in normalisation of several dynamic knee function parameters such as walking speed, knee flexion, and external knee flexion moment. As anticipated HTO reduced the varus angle and adduction moments of the operated knee. The finding of an increased adduction moment in the non-operated knee could potentially indicate an increased risk of the development of $O A$ in this joint and warrants further research. 


\section{Table 1.}

Radiographic data presention mechanical axis and weight bearing line percentages preoperatively and at 1 year follow-up.

\begin{tabular}{|l|l|l|l|}
\hline & $\begin{array}{l}\text { Pre-operative } \\
\text { Assessment } \\
\text { Mean (SD) }\end{array}$ & $\begin{array}{l}\text { Post-operative } \\
\text { Assessment } \\
\text { Mean (SD) }\end{array}$ & Significance \\
\hline $\begin{array}{l}\text { Mechanical Axis } \\
\text { (degrees) }\end{array}$ & $172(3)$ & $181(2)$ & $p<0.001$ \\
\hline $\begin{array}{l}\text { Postion of } \\
\text { weightbearing line (\%) }\end{array}$ & $10(15)$ & $56(13)$ & $p<0.001$ \\
\hline
\end{tabular}

\section{Table 2}

Peak knee kinematics in the sagittal and coronal planes for the HTO and control participants during walking

\begin{tabular}{|c|c|c|c|c|c|c|}
\hline & \multicolumn{4}{|c|}{ HTO group } & \multirow{2}{*}{$\begin{array}{c}\text { Control } \\
\text { Group }\end{array}$} & \multirow{2}{*}{$\begin{array}{c}\text { p value } \\
\text { (F ratio from } \\
\text { ANOVA) }\end{array}$} \\
\hline & $\begin{array}{l}\text { Pre-operative } \\
\text { Mean (SD) } \\
\text { HTO }\end{array}$ & $\begin{array}{l}\text { Pre-operative } \\
\text { Mean (SD) } \\
\text { Non-operated }\end{array}$ & $\begin{array}{l}\text { Post-operative } \\
\text { Mean (SD) } \\
\text { HTO }\end{array}$ & $\begin{array}{l}\text { Post-operative } \\
\text { Mean (SD) } \\
\text { Non-operated }\end{array}$ & & \\
\hline $\begin{array}{l}\text { Maximum knee flexion } \\
\text { (stance) }\end{array}$ & $11.0(8.7)$ & $18.8(5.3)$ & $19.5(5.4)$ & $21.6(6.5)$ & 19.7 (3.6 & $p<0.005^{a b}$ \\
\hline $\begin{array}{l}\text { Maximum knee flexion } \\
\text { (swing) }\end{array}$ & $55.5(4.8)$ & $57.0(6.4)$ & $58.7(4.8)$ & $58.4(4.9)$ & $57.3(4.8)$ & $p=0.29$ \\
\hline $\begin{array}{l}\text { Maximum knee } \\
\text { adduction (stance) }\end{array}$ & $13.5(4.1)$ & $7.2(3.5)$ & $5.4(3.1)$ & $8.7(4.5)$ & $6.8(2.8)$ & $\begin{array}{l}p<0.001^{c d} \\
p=0.02^{e}\end{array}$ \\
\hline
\end{tabular}

${ }^{a}$ Significant difference between pre and post-operative conditions $(p<0.02)$

${ }^{\mathrm{b}}$ Significant difference between pre-operative condition and controls $(p<0.02)$

${ }^{c}$ Significant difference between pre and post-operative conditions $(p<0.001)$

${ }^{d}$ Significant difference between pre-operative condition and controls $(p<0.001)$

${ }^{e}$ Significant difference between pre-operative and postoperative condition for the contra-lateral knee $(p=0.02)$ 
Table 3 Peak knee moments in the sagittal and coronal planes for the HTO and control participants during walking

\begin{tabular}{|c|c|c|c|c|c|c|}
\hline & & HTO & oup & & Control & p value \\
\hline & $\begin{array}{l}\text { Pre-operative } \\
\text { Mean (SD) } \\
\text { HTO }\end{array}$ & $\begin{array}{l}\text { Pre-operative } \\
\text { Mean (SD) } \\
\text { Non-operated }\end{array}$ & $\begin{array}{l}\text { Post-operative } \\
\text { Mean (SD) } \\
\text { HTO }\end{array}$ & $\begin{array}{l}\text { Post-operative } \\
\text { Mean (SD) } \\
\text { Non-operated }\end{array}$ & Mean (SD) & \\
\hline $\begin{array}{l}\text { Maximum flexor } \\
\text { moment }\end{array}$ & $1.5(1.5)$ & $3.0(1.0)$ & $3.6(1.5)$ & $4,0(1.6)$ & $3.9(1.2)$ & $\begin{array}{l}p=0.03^{e} \\
p<0.001^{a b}\end{array}$ \\
\hline $\begin{array}{l}\text { Maximum } \\
\text { extensor moment }\end{array}$ & $-2.1(1.2)$ & $-1.5(0.8)$ & $-1.5(1.2)$ & $1.9(1.0)$ & $-1.7(0.9)$ & $p=0.42$ \\
\hline $\begin{array}{l}\text { Maximum } \\
\text { adductor moment } \\
\text { (early stance) }\end{array}$ & $3.9(0.7)$ & $3.3(0.8)$ & $2.7(0.9)$ & $4.1(1.3)$ & $3.6(0.7)$ & $p=0.02^{c e}$ \\
\hline $\begin{array}{l}\text { Maximum } \\
\text { adductor moment } \\
\text { (late stance) }\end{array}$ & $3.5(1.0)$ & $3.3(0.8)$ & $1.9(0.8)$ & $4.5(1.3)$ & $2.6(0.9)$ & $p<0.001^{d}$ \\
\hline
\end{tabular}

${ }^{a}$ Significant difference between pre and post-operative conditions $(p<0.01)$

${ }^{b}$ Significant difference between pre-operative condition and controls $(p<0.01)$

${ }^{c}$ Significant difference between pre and post-operative conditions $(p<0.02)$

${ }^{d}$ Significant difference between pre-operative condition and controls $(p<0.001)$

e Significant difference between pre-operative and postoperative condition for the contra-lateral knee 


\section{Figure 1}

Sagittal plane knee angles throughout the gait cycle for the HTO and control participants during walking

\section{Figure 2}

Coronal plane knee angles throughout the gait cycle for the HTO and control participants during walking

\section{Figure 3}

Sagittal plane knee moment throughout stance phase of the gait cycle for the HTO and control participants during walking

\section{Figure 4}

Coronal plane knee moments throughout stance phase of the gait cycle for HTO and control participants during walking

\section{References}

1. Aglietti P, Buzzi R, Vena LM, Baldini A, Mondaini A (2003) High tibial valgus osteotomy for medial gonarthrosis: a 10- to 21-year study. J Knee Surg 16:21-26.

2. Andriacchi TP, Lang PL, Alexander EJ, Hurwitz DE (2000) Methods for evaluating the progression of osteoarthritis. J Rehabil Res Dev 37:163-170.

3. Andriacchi TP, Mundermann A, Smith RL, Alexander EJ, Dyrby CO, Koo S (2004) A framework for the in vivo pathomechanics of osteoarthritis at the knee. Ann Biomed Eng 32:447-457.

4. Birmingham TB, Giffin JR, Chesworth BM, Bryant DM, Litchfield RB, Willits K, Jenkyn TR, Fowler PJ (2009) Medial opening wedge high tibial osteotomy: a prospective cohort study of gait, radiographic, and patient-reported outcomes. Arthritis Rheum 61:648-657.

5. Birmingham TB, Hunt MA, Jones IC, Jenkyn TR, Giffin JR (2007) Test-retest reliability of the peak knee adduction moment during walking in patients with medial compartment knee osteoarthritis. Arthritis Rheum 57:1012-1017.

6. Briem K, Ramsey DK, Newcomb W, Rudolph KS, Snyder-Mackler L (2007) Effects of the amount of valgus correction for medial compartment knee osteoarthritis on clinical outcome, knee kinetics and muscle co-contraction after opening wedge high tibial osteotomy. J Orthop Res 25:311-318.

7. Brinkman JM, Lobenhoffer P, Agneskirchner JD, Staubli AE, Wymenga AB, van Heerwaarden RJ (2008) Osteotomies around the knee: patient selection, stability of fixation and bone healing in high tibial osteotomies. J Bone Joint Surg Br 90:1548-1557.

8. Coventry MB (1979) Upper tibial osteotomy for gonarthrosis. The evolution of the operation in the last 18 years and long term results. Orthop Clin North Am 10:191-210.

9. Davis RB (1997) Reflections on clinical gait analysis. J Electromyogr Kinesiol 7:251-257.

10. Dugdale TW, Noyes FR, Styer D (1992) Preoperative planning for high tibial osteotomy. The effect of lateral tibiofemoral separation and tibiofemoral length. Clin Orthop Relat Res 248-264.

11. Hernigou P, Medevielle D, Debeyre J, Goutallier D (1987) Proximal tibial osteotomy for osteoarthritis with varus deformity. A ten to thirteen-year follow-up study. J Bone Joint Surg Am 69:332-354. 
12. Hunt MA, Birmingham TB, Bryant D, Jones I, Giffin JR, Jenkyn TR, Vandervoort AA (2008) Lateral trunk lean explains variation in dynamic knee joint load in patients with medial compartment knee osteoarthritis. Osteoarthritis Cartilage 16:591-599.

13. Ivarsson I, Myrnerts R, Gillquist J (1990) High tibial osteotomy for medial osteoarthritis of the knee. A 5 to 7 and 11 year follow-up. J Bone Joint Surg Br 72:238-244.

14. Kadaba MP, Ramakrishnan HK, Wootten ME (1990) Measurement of lower extremity kinematics during level walking. J Orthop Res 8:383-392.

15. Kendoff D, Lo D, Goleski P, Warkentine B, O'Loughlin PF, Pearle AD (2008) Open wedge tibial osteotomies influence on axial rotation and tibial slope. Knee Surg Sports Traumatol Arthrosc 16:904-910.

16. Machner A, Pap G, Krohn A, Rohkohl K, Awiszus F (2002) Quadriceps muscle function after high tibial osteotomy for osteoarthritis of the knee. Clin Orthop Relat Res 177-183.

17. McMahon M, Block JA (2003) The risk of contralateral total knee arthroplasty after knee replacement for osteoarthritis. J Rheumatol 30:1822-1824.

18. Mundermann A, Dyrby CO, Hurwitz DE, Sharma L, Andriacchi TP (2004) Potential strategies to reduce medial compartment loading in patients with knee osteoarthritis of varying severity: reduced walking speed. Arthritis Rheum 50:1172-1178.

19. Noyes FR, Goebel SX, West J (2005) Opening wedge tibial osteotomy: the 3-triangle method to correct axial alignment and tibial slope. Am J Sports Med 33:378-387.

20. Ozalay M, Ozkoc G, Circi E, Akpinar S, Hersekli MA, Uysal M, Cesur N (2008) The correlation of correction magnitude and tibial slope changes following open wedge high tibial osteotomy. Knee Surg Sports Traumatol Arthrosc 16:948-951.

21. Parker RD (2005) Valgus-producing opening wedge proximal tibial osteotomy: what, when, and how. Orthopedics 28:977-979.

22. Prodromos CC, Andriacchi TP, Galante JO (1985) A relationship between gait and clinical changes following high tibial osteotomy. J Bone Joint Surg Am 67:1188-1194.

23. Ramsey DK, Snyder-Mackler L, Lewek M, Newcomb W, Rudolph KS (2007) Effect of anatomic realignment on muscle function during gait in patients with medial compartment knee osteoarthritis. Arthritis Rheum 57:389-397.

24. Rinonapoli E, Aglietti P, Mancini GB, Buzzi R (1988) High tibial osteotomy in the treatment of arthritic varus knee. A medium term (small) review of 61 cases. Ital J Orthop Traumatol 14:283-292.

25. Sharma L (2007) The role of varus and valgus alignment in knee osteoarthritis. Arthritis Rheum 56:1044-1047.

26. Sharma L, Lou C, Felson DT, Dunlop DD, Kirwan-Mellis G, Hayes KW, Weinrach D, Buchanan TS (1999) Laxity in healthy and osteoarthritic knees. Arthritis Rheum 42:861870.

27. Wada M, Imura S, Nagatani K, Baba H, Shimada S, Sasaki S (1998) Relationship between gait and clinical results after high tibial osteotomy. Clin Orthop Relat Res 180-188.

28. Whitehead TS, Willits K, Bryant D, Giffin JR, Fowler PJ (2009) Impact of medial opening or lateral closing tibial osteotomy on bone resection and posterior cruciate ligament integrity during knee arthroplasty. J Arthroplasty 24:979-989.

29. Zhao D, Banks SA, Mitchell KH, D'Lima DD, Colwell CW, Jr., Fregly BJ (2007) Correlation between the knee adduction torque and medial contact force for a variety of gait patterns. J Orthop Res 25:789-797. 